\title{
Posterior urethral valve
}

INSERM

\section{Source}

INSERM. (1999). Orphanet: an online rare disease and orphan drug data base. Posterior urethralvalve. ORPHA:93110

Posterior urethral valve (PUV) is the most common anomaly of fetal lower urinary tract obstruction (LUTO)and is characterized by an abnormal congenital obstructing membrane that is located within the posterior urethra associated with significant obstruction of the male bladder restricting normal bladder emptying. 